\title{
Entrepreneurial Leadership as a Determining Factor in the Internationalisation of Technology Driven Knowledge Intensive Services within Spanish SMEs
}

\author{
Juan Pablo Camus Moller ${ }^{1}$, Patricio Morcillo ${ }^{2}$, Jose Maria Fernandez-Crehuet ${ }^{3}$ \\ ${ }^{1}$ Doctoral student in Economics and Innovation Management at Universidad Autónoma de Madrid, Spain \\ ${ }^{2}$ Professor in Innovation Management at Universidad Autónoma de Madrid, Spain \\ ${ }^{3}$ Assistant Professor in Industrial Engineering at Universidad Politécnica de Madrid, Spain \\ Correspondence: Jose Maria Fernandez-Crehuet, Assistant Professor in Industrial Engineering at Universidad \\ Politécnica de Madrid, Spain.
}

Received: March 22, 2018

doi:10.11114/aef.v5i4.3124
Accepted: May 23, $2018 \quad$ Available online: June 10, 2018

URL: https://doi.org/10.11114/aef.v5i4.3124

\begin{abstract}
The aim of this research project is to generate a general framework to evaluate entrepreneurial leadership as a driving influence in the internationalisation process of a Knowledge Intensive SME and to understand behavioural patterns of entrepreneurial leadership which might influence its internationalization.

The study uses a sample of 892 small and medium enterprises (SMEs) in the technology based knowledge intensive sectors from the Spanish Technological and Innovation Panel (PITEC) to analyse the impact of three dimension of entrepreneurial leadership -entrepreneurial and managerial elements; absorptive capacity and networks elements and strategic and innovative elements- upon exports as one of those preferred vehicles for SME internationalisation. The research uses linear and logistic regressions to examine the links of the different components of entrepreneurial leadership and shows the extent of a positive relationship between the proposed constructs of entrepreneurial leadership with the internationalisation of knowledge intensive SME in Spain.
\end{abstract}

An additional value of the research is to provide a better understanding of the future of new enabling technologies for SMEs and their possible impact in any international endeavour where entrepreneurial leadership plays a critical function.

Keywords: entrepreneurial leadership, innovation, internationalisation, networks, cooperation, small and medium enterprises, Spain, knowledge intensive services, enabling technologies

\section{Introduction}

The aim of this paper is to propose a general framework based on different variables to evaluate whether entrepreneurial leadership emerges as a driving influence in the internationalisation process of a Knowledge Intensive Small/Medium Enterprise (SME) within the Spanish Innovative sector or not.

In a second stage, the derived aim is within the generated framework to validate behavioural patterns of entrepreneurial leadership which might influence the internationalisation of a technology- driven SME.

In section 2, the literature review allows us to introduce those relevant topics and concepts to be addressed during the research -internationalisation, knowledge intensive sectors, absorptive capacity, networks; cooperation; innovation, enabling digital technologies, and entrepreneurial leadership- and how these factors would be connected and be related to the internationalisation of technological-driven knowledge intensive SMEs.

The scope of the study, its methodological specifications along with segmentation criteria, classification of activities, descriptions of variables are included in section 3 .

In this section is presented as well, the development of the technical procedures and the foundations of the quantitative analysis of firms from the database of Spanish Technological Innovation Panel (PITEC).

In section 4 are presented the result from the quantitative analysis. The study results will attempt to demonstrate the 
relationship between the construct and its variables -obtained from existing studies and literature- supporting the hypothesis related to the internationalisation of technology-driven knowledge intensive SMEs and contributing to a better understanding of their internationalisation patterns under the new digital context.

Finally, in section 5 are given details of the principal findings, discussion and managerial implications, including existing limitations to extrapolate the relevant findings to other markets and sectors for further research.

\section{Theoretical Framework}

Small and Medium Enterprises (SMEs) through their economic activity constitute one of the main engines of economic growth of European welfare in general and of Spain in particular. SMEs are par excellence the backbone of the European economy, accounting for $99 \%$ of all firms, generating some $85 \%$ of new jobs, and contributing with $60 \%$ of the economy's total production. This accounts for around two-thirds of private sector employment in the European Union (European Union: Background Study for the European Competitiveness, 2014, p. 7).

SMEs according to European Union User guide to the SME Definition $(2015$, p. 10) are enterprises which: "employ fewer than 250 persons; and have either an annual turnover not exceeding EUR 50 million or an annual balance sheet total not exceeding EUR 43 million".

The level of internationalisation of European SMEs in general is low, if compared to the level of large companies. There is a vast literature relating the size of firms with the depth of internationalisation achieved (Acs \& Preston, 1997; Freeman, Hutchings, Lazaris, \& Zyngier, 2010; Johanson \& Vahlne, 1977, 2009; Madsen \& Servais, 1997; Olejnik \& Swoboda, 2012; Wolff \& Pett, 2000). However, from the 20th century onwards as a consequence of the disruptive growth of information technologies and communications, (Freeman, Edwards, \& Schroder, 2006; Gabrielsson \& Kirpalani, 2004; Madsen \& Servais, 1997; Namiki, 1988; Narasimhan, Kumar, \& Sridhar, 2015; Saarenketo, Puumalainen, Kuivalainen, \& Kyläheiko, 2004) small and particularly micro firms have shown significant increases in international activity levels through more intensive use of new digital technology (Freeman et al., 2006, 2010; Gabrielsson \& Kirpalani, 2004; Madsen \& Servais, 1997; Namiki, 1988; Narasimhan et al., 2015; Saarenketo et al., 2004).

As a matter of fact, European SMEs are becoming more multinationals (European Union: Background Study for the European Competitiveness, 2014) by using new digital platforms and enabling digital technologies (cloud computing, internet, social media, unified communications, among others), thus contributing to reduce communication costs, to improve collaboration, to provide instantaneous exchange of virtual goods and, in particular to promote their international expansion (Tania, Stefano, Chiara, Giuseppe, Michele \& Irina, 2014 and Manyika, Lund, Bughin, Woetzel, Stamenov \& Dhingra, 2016).

New business outlooks suggest internationalisation as instant action in firms which are automatically self-generating at the time of conception (Gabrielsson \& Kirpalani, 2004; Madsen \& Servais, 1997; Narasimhan et al., 2015).

Specialized literature calls them "Born Global" the genesis of which is radically opposed to the traditional model known by the Upsala gradual or evolutionary process in the internationalisation of a firm (Johanson \& Vahlne, 1977, 2009; Kogut \& Zander, 1992).

It is important to mention that a firm's international expansion provides both opportunity for growth and the capacity to acquire fresh knowledge (Hsu, Chen, \& Cheng, 2013). Furthermore, we should stress the positive relationship between SME internationalisation in manufacturing sectors with variables such as; cooperation (Zeng, Xie, \& Tam, 2010) and innovations in products and processes (Kafouros, Buckley, Sharp, \& Wang, 2008; Tidd \& Bessant, 2009).

The literature identifies exports as the most important vehicles of internationalisation in SMEs (Namiki, 1988; Woolf \& Pett, 2000) and the same rules apply for European SMEs (European Union: Background Study for the European Competitiveness, 2014). In this context, mention is made that those activities with an advanced technological base and more intensive in the use of knowledge (Schricke, Zenker, \& Stahlecker, 2012) and with more qualified and specialized technical workforce, as seen in technology, media \& entertainment, retail, financial services, telecommunications, among other sectors, possess enablers that motivate them to a faster and more effective international expansion (European Union: Background Study for the European Competitiveness, 2014; Manyika et al., 2016).

Nowadays, existing literature shows that SMEs are becoming more and more influenced by external and internal factors such as: learning, cooperation, digitalization, innovation and globalization (European Union: Background Study for the European Competitiveness, 2014; Manyika et al., 2016). All of them generate a strong impact in business development, operation and sustainability, but are of special interest in knowledge intensive sectors. For the same reason entrepreneurship and leadership cannot be separated and limited to one single dimensional perspective; on the contrary, they must be considered as the integration of multiple factors that collectively allows a better understanding of the 
phenomenon (van Zyl \& Mathur-Helm, 2007).

Entrepreneurial leadership in the literature is conceived as integrating the main characteristic of entrepreneurship and leadership (van Zyl \& Mathur-Helm, 2007) which as a whole consider having the capacity, or rather the ability to create, innovate, organize, and steer strategy, distinguished by a set of specific attributes which characterize him such as; visionary, manager, strategist, and innovator (Morcillo Ortega, 1997; Tidd \& Bessant, 2009).

In the case of knowledge intensive sectors, it is important to highlight and to bring into the context the importance of what scholars named absorptive capacity, understood as a necessary critical process required in the organization to grasp, evaluate, assimilate and apply knowledge stemming from external sources with commercial and innovative purpose (Cohen \& Levinthal, 1990). However, in small and middle size enterprises this lack of capability is clearly identified (Tidd \& Bessant, 2009).

Other aspects identified which contribute to a greater understanding of this situation are: levels of cooperation, and the use of digital tools (internet, cloud computing, big data and social marketing, wireless communication, distant learning, and social network, among others). All of them have strongly influenced the development, expansion and further internationalisation of technological innovations (Brynjolfsson \& McAfee, 2014; Manyika et al., 2016; Tania et al., 2014).

Nevertheless, despite the abundant literature mentioning internationalisation, there are few studies going deeply into those relevant factors exercised by entrepreneurial leadership that might influence the international expansion of technology-driven knowledge intensive SMEs.

The aim of this research project is not only to generate a general framework based on different variables to evaluate whether entrepreneurial leadership emerges as a driving influencer in the Internationalisation process of a Knowledge Intensive Small/Medium Enterprise (SME) within the Spanish Innovative sector or not, but also to propose a general framework to validate behavioural patterns of entrepreneurial leadership which might influence the internationalisation of a technology driven SME.

It is also of special interest to study through quantitative analysis the influence of some internal and external factors in the internationalisation behaviour of a sample of Spanish SMEs limited to the technology- driven knowledge intensive sector.

Given the above mentioned assumptions, the following variables enable us to identify the influence which would be exerted by entrepreneurial and innovative leadership on the service internationalisation of technology driven knowledge intensive SMEs.

The empirical analysis of the following constructs allows to provide a better understanding of the proposed research question:

a. The entrepreneurial and managerial dimension evaluates leadership on the basis of the following characteristics: pro-activeness, innovativeness and risk taken (Muchiri \& McMurray, 2015; van Zyl \& Mathur-Helm, 2007; Zaridis \& Mousiolis, 2014) and managerial in the sense of wealth creation, decision making, social skills, collaboration, communication and relationship building (Grant, 2013; Olejnik \& Swoboda, 2012). The entrepreneurial, innovative and managerial dimension (Schumpeter, 1934; Tidd \& Bessant, 2009) is obtained integrating the following variables: cross border sales and export intensity as indicators of export orientation of a firm (Hessels, Gelderen, \& Thurik, 2008). The investment in innovation and the average revenue contribution per employee or labour productivity shows the entrepreneurial capacities a leader possesses to integrate its technical, business knowhow, vision and resources, leading to the organisational development of value-generating activities (Grant, 2013; Gupta, MacMillan, \& Surie, 2004; Tidd \& Bessant, 2009). The role of productivity, innovation and skills as enabling forces behind export participation and export intensity. Literature highlighted that "exporters are more productive, innovative and skill intensive than non-exporters" (European Union: Background Study for the European Competitiveness, 2014 , p. 86) as they could cover all the necessary costs related with exporting. The labour productivity is also mentioned in the literature as critical enabler for the development of export activity in Spanish enterprises (Myro Sánchez, Alvarez Lopez, Fernández-Otheo, Rodríguez Rodríguez, \& Vega Crespo, 2013).

b. The absorptive capacity and network dimension is related to the incorporation, assimilation and protection of knowledge in any organization ensuring the constant flow of knowledge through the availability of external networks; high levels of collaboration with customers, suppliers or research centers, and/or R\&D activities performed in the SME (Coviello \& Munro, 1997; Johanson \& Mattsson, 2015). The roles of learning facilitator and wisdom keeper in the organization by incorporating, absorbing and securing expert knowledge allow to elaborate the absorptive capacity and network dimension of the entrepreneurial leadership construct 
(Bueno Campos, Morcillo Ortega, \& Salmador Sánchez, 2005; Cohen \& Levinthal, 1990; Grant, 2013; Tidd \& Bessant, 2009).

c. The strategical and innovative dimension accounts for the generation of innovations in their different types and forms within the organization: products or services, processes, marketing and organisational (Schumpeter, 1966). This aspect relates the influence of these variables with the strategic and creative dimension to entrepreneurial leadership. This condition could be seen in the capacity possessed by the entrepreneurial leader to influence and impinge on the adaptation and creation of new products-services, improve existing processes, generate organisational changes, and finally develop specialized marketing initiatives ensuring business profitability and sustainability. The strategic dimension also includes the ability to incorporate and to integrate new technologies as business enablers (Bueno Campos et al., 2005; Morcillo Ortega, 1997; Tidd \& Bessant, 2009).

\subsection{Internationalisation and Knowledge Intensive SMEs}

The literature defines internationalisation as the international business behaviour generated with the aim of growth orientation (Olejnik \& Swoboda, 2012) and an opportunity recognition (Chandra, Styles, \& Wilkinson, 2009) in order to achieve an economic benefit. The entrepreneurial recognition and opportunity seeking leads to use different vehicles or theories for market entry (Chandra, Styles \& Wilkinson, 2009). The most well relevant theories of internationalisation are: the Upsala gradual and incremental involvement (Johanson \& Vahlne, 1977, 2009); the OLI eclectic paradigm (Dunning, 2000) which identify international expansion as combination of three interdependent factors: ownership of the investing (O), locational attractions (L) and internalization (I); the network perspective based on exploiting relationships as a leverage for internationalisation and an entry mode in foreign markets (Coviello \& Munro, 1997; Johanson \& Mattsson, 2015), and the born global theory that conceives internationalisation on an early stage as a consequence of new digital technologies (Freeman et al., 2010; Gabrielsson \& Kirpalani, 2004; Olejnik \& Swoboda, 2012; Saarenketo et al., 2004).

Freeman et al. (2010) and Olejnik \& Swoboda (2012) in their research also supported that the Upsala model, the network approach and the Born global as preferred vehicles for SMEs internalisation. However, on the basis of their own capabilities and external factors firms take their strategic internationalisation decisions.

The traditional internationalisation models, both in the SME area and that of large firms consider increasing international intensity as a gradual, slow, incremental learning process (Johanson \& Vahlne, 1977, 2009). In this sense, the Upsala model, which explains internationalisation as an orderly and systematic process that evolves from an operation concentrated on the local market and then expands internationally in a gradual way through exports and/or foreign direct investments (Johanson \&Vahlne, 1977, 2009). The traditional model considers how long the firm has existed as a factor of suitability or maturity, and that the percentage devoted to sales or international trade is in the range of $15-20 \%$ of total sales and/or production in the case of manufacturing sectors (Madsen \& Servais, 1997).

The internationalisation of the SME linked to technologies with an intensive use of knowledge is different when compared to other industries where knowledge is used less intensively. The information technology sector has been characterised, from the nineties onwards, by a high rate of dynamism and continuous growth (European Union: Background Study for the European Competitiveness, 2014)). This is one of the main reasons why firms linked to these sectors have been characterized by making more intensive use of support networks, and external collaboration, thus showing a more rapid trend in internationalisation (Coviello \& Munro, 1997; Freeman et al., 2010; Saarenketo et al., 2004).

The rapid internationalisation of SMEs which are knowledge intensive in the digital technology sector (Knowledge intensive Hi-techs), provide empirical evidence that on these firms, the traditional incremental models based on gradual growth (Upsala) would not be applicable. In this sense, in the case of firms created following what was known as the digital era that is, at the end of the $20^{\text {th }}$ century, they were characterised as globalised firms from their beginning, and in some cases, they would be called "born global". This type of business is characterized as using a more lightweight structure and a more efficient use of resources (Madsen \& Servais, 1997).

According to the literature there are three main characteristics for the rise of Born Global which are: technological developments in production, logistic and communication; new market opportunities and people capabilities including the entrepreneurial dimension (Madsen \& Servais, 1997). Furthermore, those firms have the characteristic of the following aspects: the vision and conviction to be either global or belong to an international context; being noticeably geared to technologies and innovation; and going international in a short period of time-less than three years (Gabrielsson \& Kirpalani, 2004).

The knowledge-intensive services or KIS are in fact businesses with a high knowledge component and/or related with high-tech industry such as: telecommunications, financial services, education, health and social work, computer, 
research and development, and other related activities (Schricke, Zenker, \& Stahlecker, 2012). Another condition enabling us to characterize knowledge-intensive SMEs, is the high penetration of Internet as a tool for facilitating and integrating technology in business processes (Gabrielsson \& Kirpalani, 2004).

The dynamic growth in the knowledge intensive sector would be a direct consequence of such factors as institutional, industrial and organisational ones. In this context, regulatory changes, liberalization of markets and privatizations after the nineties have had a positive effect on growth and the rapid internationalisation of sectors with intensive knowledge (Saarenketo et al., 2004).

Among the factors that have made a significant contribution to the rapid internationalisation the following could be considered relevant: high level of specialization in their assets, consistent investments in R\&D, and fierce competition stemming from rapid obsolescence of new technologies. All of this is likely to occur within the following industries: software, hardware, business solutions, telecommunications and complementary services (Saarenketo et al. 2004).

Exports are considered one of the main channel for European SMEs internationalisation (European Union: Background Study for the European Competitiveness, 2014) and it is also mentioned in the OECD Internationalisation Report (2009, p. 12) that among Spanish drivers for SME internationalisation that "managers experience, firm size and age; regional location are the most relevant enablers" for international expansion.

Other aspects for SMEs internalisation mentioned in existing literature are related to international orientation, growth orientation, communication capability, intelligence generation capability and marketing-mix standardisation (Grant, 2013; Olejnik \& Swoboda, 2012).

\subsection{Absorptive Capacity, Networks and Cooperation}

The absorptive capacity recognizes the ability of a firm to get and to assimilate knowledge as value added for commercial use (Cohen \& Levinthal, 1990). It is also related with research and development (R\&D) activities, external networks and cooperation (Freeman et al., 2010) and tackle also human training and industrial and intellectual property.

Information and communication technologies will increase the capacity for learning and absorbing firms' knowledge (Cohen \& Levinthal, 1990). On the other hand, foreign market initiatives provide them with access to knowledge and new technologies. As a result, this condition would become a quicker way to firms' international expansion (Narasimhan et al., 2015).

Belonging to associative or business networks and/or outline collaboration plans constitutes one of the relevant factors impinging favorably on SME internationalisation (Johanson \& Mattsson, 2015).

Business networks by definition are described as: a type of inter-firm co-operation that promotes collaboration on the basis of common understanding expressed in an agreement in the form of a contract and/or written document. Through these associations firms would unify their efforts, share information and generate synergies to facilitate innovation and at the same time, allow increased competition -local and international (Coviello \& Munro, 1997 and Johanson, \& Mattsson, 2015). The model for co-operation would be essentially suited for any type of firm, sector and size (Fernández de Arroyabe \& Arranz Peña, 1999).

Business networks have strategic-operative aims of varying types and mainly centered upon activities such as: strengthening innovation, internationalizing businesses and/or mediation. In the case of operative aims, these could be quite varied and linked to providing specific services (legal, financial, purchasing, protection of industrial and intellectual property, etc.). The use of networks to generate alliances and collaboration would be another of the aspects mentioned in the literature of great importance for internationalizing SMEs. The seeks for savings in costs and improvements in the quality -products or services- is considered a critical enabler contributing in the development of alliances and collaboration with third parties and most especially with suppliers (Freeman et al., 2006).

Relations of collaboration are also explained by commercial interchanges produced between firms, leading to better quality in products and services. Development and strengthening of collaboration would involve building long-term strategic relationships the results of which are always worth measuring with such synthetic measures as; levels of satisfaction, loyalty, contribution, among other aspects (Gabrielsson \& Kirpalani, 2004).

SMEs in knowledge intensive sectors should exploit and have available the experience and knowledge acquired by other firms, through collaborative relationships. Such actions even facilitate and/or accelerate access to international markets (Saarenketo et al., 2004). It is also mentioned that networks and alliances enable to overcome constraint, speeding up the process of internationalisation.

\subsection{Innovation and Enabling Digital Technologies}

Several researches have analysed the existing connection between innovation and internationalisation (Hessels et al., 2008 and Kafouros et al., 2008) and between entrepreneurship and innovation (Schumpeter, 1934 and Tidd et al., 2009). 
International diversification allows firms to access information and knowhow generated in other context, integrating them in new products, processes and marketing tactics (Kafouros et al., 2008).

Digital technology changes deemed fundamental for the growth and competitiveness of nations are taking place at an ever-increasing speed. At the same time, in the case of SMEs, this new condition would generate opportunities for innovation, growth and employment (European Union: Background Study for the European Competitiveness, 2014 and Manyika et al., 2016).

Other aspect identify in the contemporary literature, is the relevance of Internet along with digital technologies as a central pillar which is changing life and the way in which people, communities and especially how SME organisations relate with each other. The intensive use of the Internet, digital tools and the respective use of technology platforms mean that new firms will use knowledge and new technologies in more intensive ways (Brynjolfsson \& McAfee, 2014; Manyika et al., 2016; Tania et al., 2014). Furthermore, access to broadband, use of internet, and other digital technologies are directly related to the level of internalization of European SMEs, especially related to international trade (Gabrielsson \& Kirpalani, 2004 and Tania et al., 2014).

Studies based on technology-based SMEs in India, enable us to understand in a better way the level of influence exercised by the new digital tools in the growth and technological development of nations (Narasimhan et al., 2015; Todd \& Javalgi, 2007). Both researches show the strong existing connection between digital technologies and a rapid internationalisation in technology driven knowledge intensive SME.

The research study from Escolano-Utrilla \& Escalona-Orcao (2017) also mentions the growth and importance of Knowledge Intensive Services (KIS) for the Spanish economy and diversification after the 2008 crisis.

Likewise, digital technologies would produce a series of benefits in firms, as a product of optimisations in the business process and/or through other marketing and commercial initiatives (Tidd \& Bessant, 2009). Such improvements would finally lead to reductions in transaction and supply costs, making inter-organisation communication and new products and services development easier. All of this will produce the consequent impacts in growth and profitability in businesses (Todd \& Javalgi, 2007).

In some way these factors condense the importance and influence that technology would have in the growth of SMEs, and it would illustrate how the latter would relate to innovation, which would be either through creation of new products and services or from improved processes and/or setting up new systems of organisation, and/or through the development of new marketing activities (Gabrielsson \& Kirpalani, 2004).

SMEs that are more internationally active have a greater impact on the development of new products and services and have better results since they can increase independently of their size the demand for products and services. Openness also brings additional indirect benefits as internalization favours learning and innovation. The same condition can be identified on the side of process innovations. This existing link between internationalisation and innovation is also shown in the European SME Internationalisation research (2010).

\subsection{Entrepreneurial Leadership in Knowledge Intensive SMEs}

There are abundant articles and definitions on the importance of leadership, how it is conceptualized and, on the impact the latter has in organizations regardless of size, the industrial sector and the field of activity where they operate. We also found a link between entrepreneurship and leadership in innovativeness and opportunity exploitation (Jones \& Crompton, 2009). The entrepreneurial and managerial dimension evaluates leadership on the basis of different factors as: pro-activeness, innovativeness and risk taken (Muchiri \& McMurray, 2015; Schumpeter, 1934; Van Zyl \& Mathur-Helm, 2007 and Zaridis \& Mousiolis, 2014), and managerial in the sense of wealth creation, decision making, and social skills -collaboration, communication and relationship building (Grant, 2013 and Olejnik \& Swoboda, 2012).

In the literature, the entrepreneurial dimension considers the importance of some specific factors or indicators known as: business size, sales/revenues, skilled personnel (productivity), and usage of innovation, among other factors (Hessels et al., 2008).

Fernandez-Ortiz \& Lombardo (2009) in a survey over 219 SMEs from La Rioja in the Spanish north-middle region established that international diversification is positively related with international experience and foreign language proficiency of their managers, confirming a link between experienced management and internationalisation.

Leadership should be distinguished from management, an aspect which sometimes is broken down in the literature, albeit in the case of SMEs it would be essentially important for all these aspects to be duly integrated. Similarly, leadership in the literature is characterized by both aspects. On one side is the responsibility defining the mission and the culture of the organization, and on the other its ability to boost achievement through a vision of the firm (Morcillo Ortega, 1997).

Among the principal attributes of the entrepreneurial-leader it is possible to identify the following aspects: visionary, 
definer, and author of the mission, creative, model of values, transformer and finally, and capable of convincing and mobilizing the organization (Gupta et al., 2004; Jones \& Crompton, 2009; Morcillo Ortega, 1997).

In addition, entrepreneurial leadership can also be explained as a structuring force allowing firms to integrate strategy both with internal factors (related with organization), and external ones (environment), generating the necessary conditions to deal better with improving method, changes in market conditions, appearance of new technologies, development of new products and services and transformational changes needed in order to mutate and adapt the firm to the new local and international context (Chandra et al., 2009; Morcillo Ortega, 2007; Muchiri \& McMurray, 2015; Tidd \& Bessant, 2009).

The outline diagram of how these factors are interrelated can be seen in Diagram Figure 1.

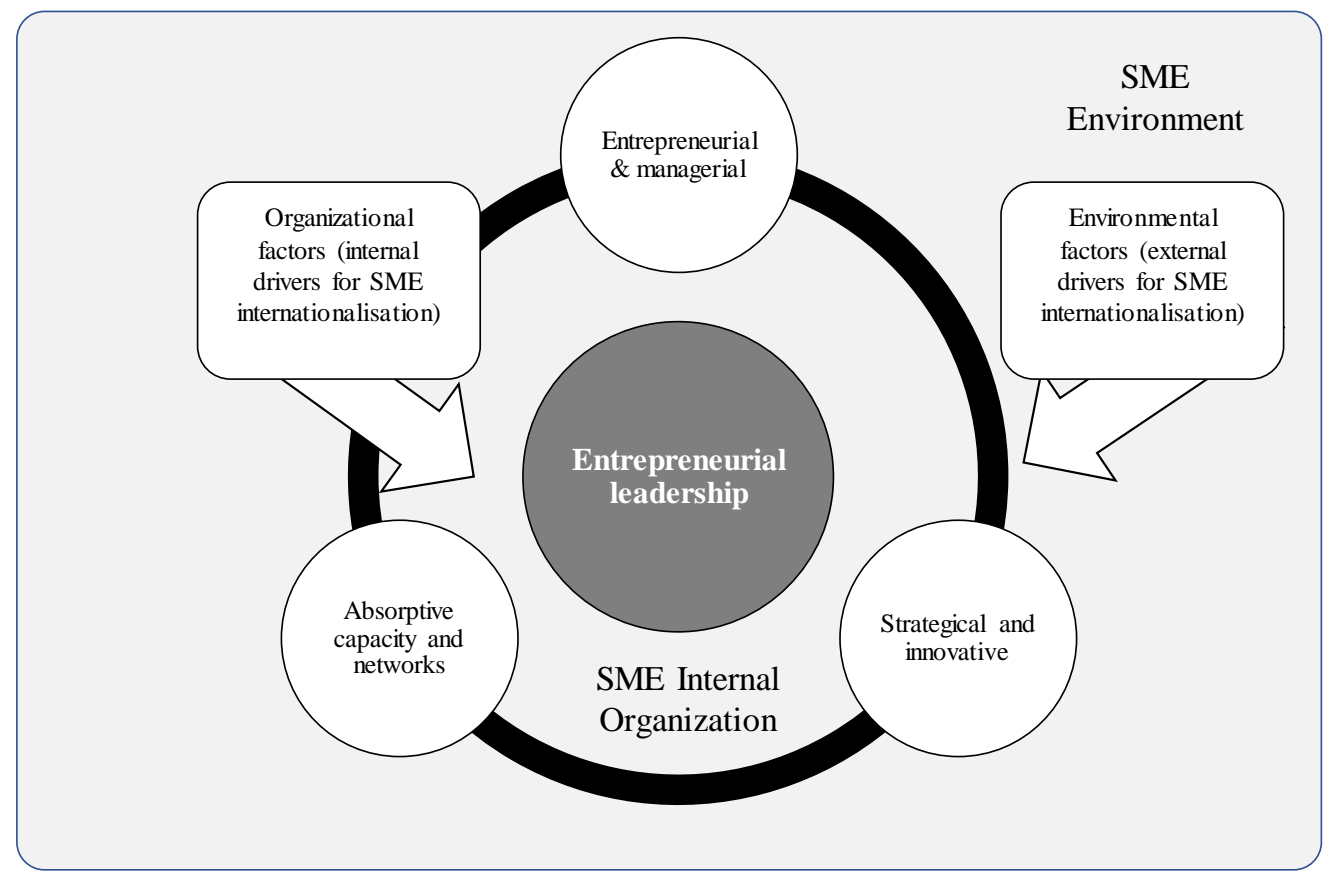

Figure 1. Drivers for SME internationalisation and entrepreneurial leadership enablers

Source: Develop by the authors

Moreover, Morcillo Ortega (2007) in his work mentions the importance attached to the leader figure in the creating and reinforcing of relational capital in the organization, which would be essentially important in firms operating in knowledge intensive sectors, for example, those linked to information technologies.

That is why essentially innovative SMEs should develop an entrepreneurial leadership to lead them towards high level actions, thus, connecting them with the organizational excellence through: innovation; customer care and people commitment (Jones \& Crompton, 2009). All of this is aimed at creating value, consolidating and creating an organizational culture that fosters creativity, learning and innovation (Morcillo Ortega, 2007; Tidd \& Bessant, 2009).

\section{Methodology and General Aspects of the Study}

The study of the main research question and its subsequent analysis is carried out by integrating in a model several variables coming from theoretical frameworks in existing literature incorporated in three specific entrepreneurial leadership dimensions: entrepreneurial and managerial; absorptive capacity; and strategic and innovative.

The research methods that supported the quantitative analysis are found in the following literature: Patton (1990), Corbetta (2003) and Trochim \& Donnelly (2005). Additionally, the data modeling utilized de SPSS statistical and analytical software supported by Muijs (2010) quantitative research in education was done with SPSS guidelines.

The methodology considers both the revision of existing theoretical frameworks and documents, and the quantitative analysis from the data provided by the Spanish Technological Innovation Panel (PITEC). PITEC is a joint initiative among the National Research Bureau (INE), the Spanish Foundation for Science and Technology (FECYT) and the Foundation COTEC (FECYT; INE, 2016). The study uses a sample of 892 Spanish small and medium-sized Spanish firms (SMEs) according European Union user guide to the SME definition (2015, p. 10) in the technology based knowledge intensive sectors to examine the impact of three elements of entrepreneurial leadership (entrepreneurial and managerial; absorptive capacity and networks; strategic and innovative) upon exports (internationalisation). 
The criteria used to characterize firms by levels of intensity in the use of knowledge is the CNAE-2009 typification of the National Research Bureau (INE, 2009). The details of these entries are individualized in Appendix 1, and the only firms considered are those operating in knowledge-intensive sectors and/or while being at the same time active in technology use. These firms in the literature are named "technology-based" corresponding to those sectors linked to the development of activities using technology, supporting research and development (R\&D), and/or management of innovation (Schricke et al., 2012, p. 26).

\subsection{Variables Definition}

The study of the research question and its subsequent analysis is supported on the quantitative analysis of three dimensions of entrepreneurial leadership associated with the following leadership characteristics: a) entrepreneurial and managerial; b) absorptive capacity and network/collaboration; and c) strategic and innovative. These aspects would be used as a reference to evaluate the influence that the entrepreneurial leadership would have on the international expansion of an SME which is technological and knowledge intensive.

As follow is described how each of the variables are integrated in the proposed model:

a. entrepreneurial and managerial dimension (Group 1): this construct based on previous literature seeks to identify the relationship existing between the entrepreneurial leadership and growth creation through exports, productivity and innovation.

b. absorptive capacity and networks dimension (Group 2): these variables found in proposed literature attempt to link the entrepreneurial leadership with knowledge generation (I+D), absorption (training), protection (patents and intellectual copyrights) and transfer (networks and collaboration).

c. strategic and innovative dimension (Group 3): this aspect relates he influence of entrepreneurial leadership according to existing literature in value creation by innovation (product/services, commercial, process and organizational.

Additional aspects which complement the model and relate internationalisation of services are: number of employees (size) and how long the firm had been operating (aging). Figure 2, enables us to visualize the research framework and how it interrelates with the different identifies dimension of entrepreneurial leadership which would be tackled in the mentioned model.

The sets of variables used along with the respective indicators used in the study are explained in Appendix 3.

\begin{tabular}{|c|c|c|c|c|c|c|c|c|c|c|c|}
\hline \multicolumn{12}{|c|}{$\begin{array}{c}\text { Entrepreneurial \& innovative leadership as a determining factor in the Internationalisation of } \\
\text { Technology-driven Knowledge Intensive Services within Spanish SMEs }\end{array}$} \\
\hline \multicolumn{4}{|c|}{$\begin{array}{l}\text { a) Entrepreneurial \& managerial } \\
\text { dimension (Schumpeter, 1934; Van Zyl \& } \\
\text { Mathur-Helm, 2007; Tidd, Bessant, \& } \\
\text { Pavitt, 2009; Olejnik \& Swoboda, 2012; } \\
\text { Grant, 2013; Zaridis \& Mousiolis, 2014) }\end{array}$} & \multicolumn{4}{|c|}{$\begin{array}{l}\text { b) Absorptive capacity and networks } \\
\text { dimension (Cohen \& Levinthal, 1990; } \\
\text { Morcillo, 1997; Bueno et al., 2005; Tidd, } \\
\text { Bessant, \& Pavitt, } 2009 \text { and Grant, 2013) }\end{array}$} & \multicolumn{4}{|c|}{$\begin{array}{l}\text { c) Strategical and innovative } \\
\text { (Schumpeter, 1966; Morcillo, 1997; } \\
\text { Bueno et al.,2005 and Tidd, Bessant, \& } \\
\text { Pavitt, 2009) }\end{array}$} \\
\hline 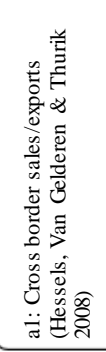 & 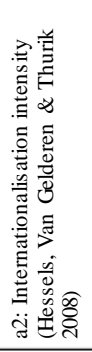 & 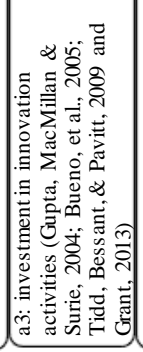 & 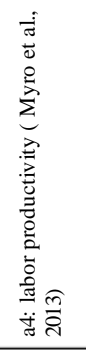 & 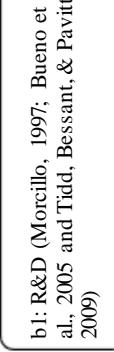 & 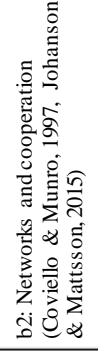 & 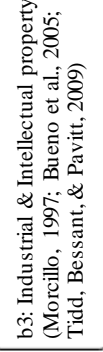 & 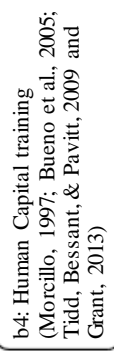 & 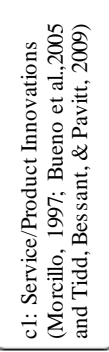 & 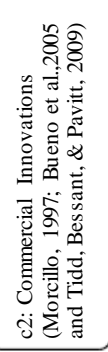 & 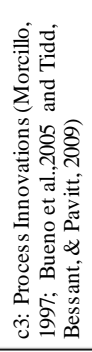 & 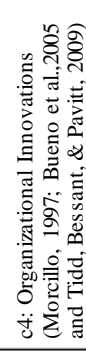 \\
\hline
\end{tabular}

Figure 2. Research framework based on literature review

Source: Develop by the authors

\subsection{Data model and Segmentation Criteria}

The PITEC data panel used records information from various activities related to management, knowledge absorptive, and innovation developed by Spanish firms in a calendar year. Information comes from the 2013 innovation survey 
carried out by PITEC on a universe of 12,833 Spanish firms.

The number of firms was chosen after the application of the following selection criteria: being active in terms of business activity, and a volume of revenue according to SME definition (European Union user guide to the SME definition, 2015). The initial segmentation generated 7,522 Spanish SMEs from different industries and sectors. Then another criterion was taken into account in order to select only those SMEs which were in the target segment of technology driven and knowledge intensive firms.

The segmentation criteria utilized to characterize firms by levels of intensity in the use of knowledge is the CNAE-2009 format (National Research Bureau (INE) for 2009). This schema provides the following sectors and codes: Telecommunications (0032), Programming, Consultancy and Other Informatics Activities (0033), Other Services of Information and Communications (0034) and R\&D Services (0037). The details of these entries are individualized in Appendix 1, and the only firms considered are those operating in knowledge-intensive sectors and/or while being active in the use of technology (Escolano-Utrilla \& Escalona-Orcao, 2017 p. 62). These firms in the literature are named "technology-based" linked to those sectors that develop activities using an intensive use of technology as: research and development (R\&D), and/or management of innovation (Schricke et al., 2012, p. 26).

As a result of these applied criteria a final sample of 892 technological driven knowledge intensive SME was produced.

\section{Results and Quantitative Analysis}

The descriptive procedure in Table $\mathrm{N}^{\circ} 1$ shows the statisticians who summarise the behaviour of variables in one sole table (mean, typical deviation and sample size), and which allow the variables to be compared.

In this case, the 892 SMEs with a, presented continuous variables with a typical considerable deviation from the mean (turnover, work productivity, export intensity, export turnover, expenditure in innovations and size) the size of the deviation for this set of variables indicates the existence of a great difference with regard for minimum and maximum values in the group of firms constituting the sample.

Table 1. Summary of descriptive statistics

\begin{tabular}{lrrr}
\hline Variables & Mean & $\begin{array}{c}\text { Typical } \\
\text { deviation }\end{array}$ & $\begin{array}{c}\text { Sample } \\
(\mathbf{N})\end{array}$ \\
\hline Ln(exportturnover_total+1) & 5,611 & 6,392 & 892 \\
Turnover & $4.781 .570,5$ & $8.086 .191,4$ & 892 \\
Labour Productivity & $81.726,3$ & $129.863,8$ & 892 \\
Export_intensity & 0,131 & 0,261 & 892 \\
Gtinn & $927.704,3$ & $2.941 .230,2$ & 892 \\
Size & 73,8 & 171,2 & 892 \\
When founded & 18,27 & 9,18 & 892 \\
R\&D & 0,586 & 0,493 & 892 \\
Training & 0,145 & 0,352 & 892 \\
Cooperates & 0,381 & 0,486 & 892 \\
industrial_intellectual_protection & 0,242 & 0,429 & 892 \\
Innprod & 0,455 & 0,498 & 892 \\
Innproc & 0,346 & 0,476 & 892 \\
Inorgn & 0,388 & 0,488 & 892 \\
Incomn & 0,315 & 0,465 & 892 \\
\hline
\end{tabular}

Source: Panel of Technological Innovation (PITEC), 2013

Note*: the variable dependent is individualized by the expression $\ln ($ exportturnover_total +1$)$ in which calculated value corresponds to the neperian logarithm of the figure for total exports (exportturnover_total) normalized (the value 1 is added).

Furthermore, the bivariate correlations procedure, measured by the Pearson correlation coefficient (Spearman rho and Kendal tau-b with their signification levels) would enable us to corroborate that the variables under analysis have a linear association.

\subsection{Linear Regression}

The statistical analysis uses linear regression to estimate the coefficients of the equation which would best predict the value of the dependent variable. Through this measure, we would seek to identify the causal relationship existing between the entrepreneurial leadership and the internationalisation of technology driven knowledge intensive SMEs. The quantitative linear regression analysis would corroborate the veracity of the hypotheses by linking those selected variables that explained the entrepreneurial leadership construct (entrepreneurial and managerial; absorptive capacity and networks; and strategic and innovative) with the internationalisation of a technology driven knowledge intensive 
SME.

Internationalisation is represented by exports of services as a dependent variable (ln_export turnover_total +1$)$, this in turn is explained by the behaviour of the set of independent variables used to represent entrepreneurial leadership.

The variables used for such effects are: turnover, work productivity, exporting intensity, expenditure on innovation, date of firm's foundation, R\&D activity, training, cooperation, industrial and intellectual protection and, by innovation in its different guises (products, processes, organisational, and marketing).

The linear regression would be made up of the following model:

$$
\mathrm{Y} \_\mathrm{i}=\beta \_0+\beta \_1 \mathrm{X} \_\mathrm{i} 1+. .+\beta \_\mathrm{k} X \_\mathrm{ik}+\varepsilon_{-} \mathrm{i}
$$

where

Y_i: dependent variable.

$\beta \_0$ : constant or intersection of the straight line with the axis Y.

$\beta \_1 . . \beta$ k: respective parameters of each independent variable.

$\mathrm{X} \_\mathrm{i}$ : number of firms in the e sample associated with the technology driven knowledge intensive SME segment.

The linear regression is made to a total of 892 registers stemming from the PITEC segmented base in accordance with the above-mentioned selection criteria.

The dependent variable is: $\ln$ (export turnover_total +1 ). The export turnover is defined as the main vehicle for internationalisation within this aim of this research.

The predictive or independent variables are: turnover, work productivity, export intensity, gtinn, size, date of foundation, R\&D, training, cooperation, industrial and intellectual protection, innprod, innproc, inorgn, incomn. All the independent variables considered in the model are defined and explained in Appendix 3.

The factors present a positive, moderate correlation as indicated in Table $\mathrm{N}^{\circ} 2$. The positive significance in the correlation of the factors would be given by the value 0.719 of R; moreover, the value 0.52 of R2 would mean that more than half of the independent variables would be explained by the behaviour of the formulated construct. By the same token, it can be induced from this that there would be a considerable positive relation between the internalization (exports) and the set of variables associated with entrepreneurial leadership.

The signification level for the set of main valuables, as expressed in Table $\mathrm{N}^{\circ} 3$ is found in the range (**). This condition would enable us to infer that the construct relating the entrepreneurial leadership with internationalisation of the SME would finally be accepted.

Table 2. Summary of the linear regression model

\begin{tabular}{lrrrr}
\hline Model & R & R squared & $\begin{array}{l}\text { Corrected R } \\
\text { squared }\end{array}$ & $\begin{array}{l}\text { Typical } \\
\text { estimation error }\end{array}$ \\
\hline Linear Regression & 0,719 & 0,517 & 0,510 & 4,4764312 \\
\hline
\end{tabular}

Table 3. Coefficients of the linear regression model

\begin{tabular}{lrrrrr}
\hline Variables & B & $\begin{array}{c}\text { Typical } \\
\text { error }\end{array}$ & T & $\begin{array}{c}\text { Significance } \\
\text { /P.Value. }\end{array}$ \\
\hline (Constant) & 0,843 & 0,415 & 2,030 & 0,043 & $* *$ \\
Turnover & $7,835 \mathrm{E}-08$ & $2,569 \mathrm{E}-08$ & 3,049 & 0,002 & $* *$ \\
Work_productivity & $4,252 \mathrm{E}-06$ & $1,237 \mathrm{E}-06$ & 3,436 & 0,001 & $* *$ \\
Export_intensity & 14,609 & 0,608 & 24,036 & 0,000 & $* *$ \\
Gtinn & $1,207 \mathrm{E}-07$ & $5,593 \mathrm{E}-08$ & 2,157 & 0,031 & $* *$ \\
Size & 0,003 & 0,001 & 2,318 & 0,021 & $* *$ \\
When founded & 0,032 & 0,017 & 1,893 & 0,059 & \\
R\&D & 0,551 & 0,380 & 1,452 & 0,147 & \\
Training & 0,151 & 0,472 & 0,320 &, 749 & \\
Cooperates & $-0,407$ & 0,374 & $-1,087$ & 0,277 & $* *$ \\
Industrial_intellectual_protection & 1,067 & 0,389 & 2,741 & 0,006 & $* *$ \\
Innprod & 0,598 & 0,369 & 1,623 & 0,105 & \\
Innproc & $-0,148$ & 0,380 & $-0,389$ &, 697 & $* *$ \\
Inorgn & 0,948 & 0,361 & 2,626 & 0,009 & $* *$ \\
Incomn & 0,654 & 0,378 & 1,731 & 0,084 & \\
\hline
\end{tabular}

(*) Significance value less than or equal to $0,001(1 \%)$. I.E. confidence level of this variable would be less at $1 \%$ respectively 
(**) Significance value less than or equal to 0,05 (5\%). I.E. the confidence level of this variable would be less at $5 \%$, respectively

\subsection{Logistical Regression (Logic)}

The logistical regression would be used to predict the result of the dependent variable of dichotomical character, according to the values of the set of predictive variables. The coefficients of logistical regression would enable the model to evaluate the reason for the advantages of each group of independent variables associated with the working hypothesis or preliminary research questions. The group of these variables is aimed at identifying whether the dependent variable (if they export) would be influenced by group 1 (independent variables representing the entrepreneurial and managerial construct stated in section 3.1 a) by group 2 (independent variables representing the absorptive capacity and networks construct stated in section $3.1 \mathrm{~b}$ ) and/or group 3 (variables associated with the strategic and innovative construct stated in section $3.1 \mathrm{c}$ ).

The logistical regression is made up of the following model:

$$
P(Y=1)=\frac{1}{1+e^{\left(-\alpha-\beta_{1} X_{1}-\beta_{2} X_{2}-\ldots-\beta_{k} X_{k}\right)}}
$$

where

Y: dependent variable of dichotomical character (export).

$\alpha$ : constant or intersection of straight line with axis Y.

$\beta \_1 . . \beta$ k k:independent explanatory variables (turnover, work productivity, export intensity, gtinn, size, date of foundation, $\mathrm{R} \& \mathrm{D}$, training, cooperation, industrial and intellectual protection, innprod, innproc, inorgn, incomn).

$\mathrm{X} \_\mathrm{k}$ : number of firms associated with the sample in the segment SME of base technology and intensive in knowledge.

e: exponential function or constant Euler number with approximate value of 2.718 .

The logistical regression would be made to a total of 892 registers coming from the PITEC segmented base in accordance with those mentioned selection criteria.

Table 4 shows the coding for the variables where 1 signifies that the firm is an exporter of services and 0 would imply that the firm does not export (does not export). Also, it would signal the absolute frequency for each value where the percentage of exporting firms in this segment would be $54.1 \%$.

Table 4. Classification Table

\begin{tabular}{llrrrr}
\hline Observed & & \multicolumn{3}{c}{ Predicted } \\
& & They export & \multicolumn{2}{c}{ Percentage } \\
& & 0 & 1 & \multicolumn{2}{c}{ correct } \\
\hline They export & 0 & 0 & 409 & 0,0 \\
& 1 & 0 & 483 & 100,0 \\
Global percentage & & & 54,1 \\
\hline
\end{tabular}

In Table 5 is shown a summary with the regression results. The result of the measure ( $-2 \log$ of plausibility) would indicate that it is a low number, insofar as the deviation of the data would be of a lesser type and the adjustment of the variable would be better. Moreover, Cox and Snell's R squared value (value between 0 and 1) makes it possible to identify that $44.5 \%$ of the dependent variable (they export) would be explained by the variables considered in the proposed model.

In the same way, Nagelkerke's R squared (a corrected version of Cox and Snells'R squared) improves the statistical scale, allowing at the same time an identification of approximately $59.5 \%$ of the dependent variable "They export" to be explained by the independent variables incorporated in the model.

As a result of the above, the existing forerunners would enable us to infer that the model and dependent variables used has a positive relationship between the selected construct of entrepreneurial leadership and internationalisation of services in the technology driven knowledge intensive SME.

In this context, the set of variables selected to characterize the entrepreneurial leadership construct shows a positive relation among them. This output provides valuable information that allows a level of connection to be found between entrepreneurial leadership and export internationalisation in the technology driven knowledge intensive SME segment.

Table 5. Summary of the logistical regression model

\begin{tabular}{lccccr}
\hline Stage & $\begin{array}{c}-2 \log \\
\text { likelihood }\end{array}$ & $\begin{array}{l}\text { Cox \&Snell' } \\
\text { squared }\end{array}$ & $\begin{array}{l}\text { Nagelkerke' } \\
\text { squared }\end{array}$ & R \\
\hline 1 & $705,059^{\text {a }}$ & & 0,445 & & 0,595 \\
\hline
\end{tabular}


Hosmer and Lemeshows' proof enables an evaluation to be made of the goodness of the logistical regression model and a check made on whether the proposed model would make it possible to explain what was observed for this set of variables. Consequently, the goodness of fit according to Hosmer and Lemeshows'procedure would give rise to an adequate result given the similarity existing between expected values and observed ones.

The statistical analysis of the groups of independent variables enables us to identify the positive relationship existing among the selected group of variables. This statement is corroborated by substituting in the logistical regression model estimated "B" parameters which are individualized below in Table $\mathrm{N}^{\circ} 6$.

Table 6. Variables in the equation of the logistical regression

\begin{tabular}{llllllr}
\hline Step 1a & B & E.T. & Wald & gl & Sig. & $\operatorname{Exp(B)}$ \\
\hline $\begin{array}{l}\text { Group 1:turnover, } \\
\text { work_productivity }\end{array}$ &, 000 &, 000 & 2,051 & 1 &, 152 & 1,000 \\
$\begin{array}{l}\text { Export_intensity, } \\
\text { gtinn, size and when founded }\end{array}$ & & & & & & \\
$\begin{array}{l}\text { Grupo 2:R\&D, cooperate, } \\
\text { training }\end{array}$ &,- 435 &, 673 &, 418 & 1 &, 518 &, 647 \\
$\begin{array}{l}\text { industrial_intellectual and } \\
\text { proteccion }\end{array}$ & & & & & & \\
$\begin{array}{l}\text { Grupo 3: innprod, innproc, } \\
\text { inorgn e incomn } \\
\text { Constant }\end{array}$ &, 343 &, 351 &, 954 & 1 &, 329 & 1,409 \\
\hline
\end{tabular}

Note (a). Variable(s) introduced in stage 1: when founded*, turnover*, gtinn*, export_intensity*, work_productivity*, size, R\&D*, cooperate*, training* industrial_intellectual_protection, incomn*, innproc*, innprod*, inorgn.

Note*: the variable dependent is individualized by the expression $\ln$ (exportturnover_total+1) in which calculated value corresponds to the neperian logarithm of the figure for total exports (exportturnover_total) normalized (the value 1 is added).

The value resulting from this calculation would indicate the probability associated with (they export" $(\mathrm{P} / \mathrm{Y}=1)$ which for the segment of firms considered in the sample would be $0.7258(72.58 \%)$. Consequently, since the value 0.7258 is greater than 0.5 and near to 1, a technology driven knowledge intensive SME is likely to "export" on a similar scenario.

Finally, both the simple and logistic linear regressions are both consistent in the sense that the proposed independent variables that support the entrepreneurial leadership construct have a positive relation among them. Then based on given constructs it would be possible to deduct an existing plausible relation between the entrepreneurial leadership and the internationalisation via exports of technology driven knowledge intensive SMEs.

\section{Conclusions}

\subsection{Theoretical Implications}

In general terms, the theoretical framework provides reliable information related with those preferred vehicles for SME internationalisation within the knowledge intensive sector. In the case of Spanish SMEs, they are still expanding internationally, mainly through exporting industrial elaborate goods under the traditional evolutionary process (Myro et al., 2013). However, due to big changes in the information and communication technologies (ICT) sector more technology driven SMEs are becoming more globalized through the ongoing integration between internet enabling technologies and marketing activities (European Union: Background Study for the European Competitiveness, 2014, Tania et al., 2014, Manyika et al., 2016). For that reason, it would be important for Knowledge Intensive SMEs to develop networks and to establish binds that enable a good level of cooperation and collaboration among the different business stakeholders. Several studies outline the different perspective of the relevance and/or the future influence that networks would have over the internationalisation process especially for technology driven knowledge intensive SMEs (Coviello \& Munro, 1997; Freeman et al., 2006 and Johanson \& Mattsson, 2015).

The role of enabling technologies is crucial and will be fundamental in the internalisation of knowledge intensive SMEs, where new collaborative and digital tools such as cloud computing, social networks and other internet-based technologies will allow SMEs to become more efficient, productive and competitive (Carr, 2015; Manyika et al., 2016).

On top of those enabler factors, the role and the importance of entrepreneurial leadership for the SMEs internationalisation are still not very well defined. This statement is specially backed in some of the relevant literature where the common understanding of the entrepreneurial leadership for example in Spain is related to managerial attributes (Fernández-Ortiz \& Lombardo, 2009). On the contrary, in the knowledge intensive SME cluster, entrepreneurial leadership is more related to: productivity, operational efficiency, knowledge absorption, and most 
particularly in risk taken by the ability to bring continuous innovation into the business (Morcillo, 2006, Chandra et al., 2009, Tidd et al., 2009, and Freeman et al, 2010).

Moreover, the analysis coincides insofar as the SMEs, which are globalised must be able to adapt better to new technological challenges as well as to overcome cultural barriers from the markets and sectors where they are located (Tidd et al., 2009).

From the PITEC sample point of view, the set of variables utilized in this analysis shows a degree of positive correlation for both the lineal and the logic regression models which implies that the defined entrepreneurial leadership construct and its selected variables are well enough structured. In this case, we could assume that the Spanish technology driven knowledge intensive SMEs present certain characteristics which would differentiate them from other sectors by being more innovative, cooperative and entrepreneurial.

What is more, it can be identified that the work of the leader appears to be geared both to creation, maintenance and developing external networks. The latter is important for ensuring the constant knowledge flow to the organization.

\subsection{Managerial Implications}

First, the new digital technologies emerge as enabling tools that contribute to minimize cultural barriers, to improve communication and to facilitate the knowledge and information management within any organization, independently of their size and sector. Second in this complex scenario, there emerges the importance of the entrepreneurial leadership and its influences in productivity improvements, operational efficiency, and in the ability to promote innovation and to exploit knowledge in other markets, this is especially for Spanish SMEs in those with close cultural boundaries (Johanson \& Vahlne, 1977, 1999 and Kogut \& Zander, 1992).

Spanish SMEs needs to leverage their knowledge absorptive capacity -acquisition, protection and transfer- in order to keep successfully expanding their business into new foreign markets.

Then, as a main conclusion, the international expansion and the growth seeking of knowledge intensive firms involve important challenges in the direction and management of Spanish SMEs. In this sense it would require special entrepreneurial leadership skills to promote and to develop initiatives centered upon learning, that facilitate collaboration among organisations, and that contribute to the integration of the firm and its services in a more globalized sphere.

The importance of possessing an entrepreneurial leadership in knowledge intensive sectors lies in the need to strengthen the absorptive of knowledge, stimulate the creation of new products and services, contribute to the process of continuous improvement, transform existing organisational structures and generate marketing tools to ease successful commercialization of services in the market. The entrepreneurial leadership, in turn, takes advantage of new digital technologies to extract, relate, improve and structure knowledge in order to incorporate it in the organization where it would be transformed into growth and expansion for the firm.

Effective entrepreneurial leadership is conceived in the literature as that possessing the capacity, or rather the ability to create, to organize and to lead strategy, by distinguishing a set of specific attributes that are essentially characteristic of it. These are among others to be: visionary, manager, organizer, strategist and innovator (Morcillo, 2006, Chandra et al., 2009 and Tidd et al., 2009), and by the same token the behaviour of Spanish SMEs especially in the technology sector appears more and more imbued with a multinational and multicultural identity. This new reality compromise greater levels of cooperation and long-term relationship, training of human capital and the imperative need for permanent innovation and for securing the constant flow of knowledge coming into the firm (Coviello \& Munro, 1997; Freeman et al., 2006 and Johanson \& Mattsson, 2015).

For that reason, it is relevant for entrepreneurial and innovative leaders to be able to adapt to the technological and cultural challenges that arise because of knowledge exploitation. In this new scenario, the relevance of the entrepreneurial leadership as the responsible agent that integrates, ensuring the constant flow of knowledge within the organization.

\subsection{Limitations of the Study}

The article theoretically presents a connection with some of the identified constructs (entrepreneurial and managerial dimension; absorptive capacity and networks dimension; and strategic and innovative dimension); however, the research design has some limitations as it uses a database that was not originally formulated for developing the elaborated construct of entrepreneurial leadership. The PITEC panel is mainly related with innovation, collaboration, networks and industrial property rather than a source for addressing more specific entrepreneurial and/or managerial implications. 
Nevertheless, despite the facts of its limitations, the construct entrepreneurial leadership was tested allowing some degree of extrapolation regarding the impact of the model in the internationalisation of knowledge intensive SMEs through networks, collaboration and innovation.

\subsection{Directions for Future Research}

Finally, new lines of research emerge in relation with both the proposed framework for entrepreneurial leadership and for the internationalisation of knowledge intensive Spanish SMEs. In the case of entrepreneurial leadership, it would be interesting for further researches to incorporate other variables in order to enrich the model (organizational culture, leadership style, digital technology intensity, among others) and in the case of internationalisation to validate the influence of other variables as: imports, direct investment, join initiatives, and others) regardless of the size, location and business sector. The other aspect that was not possible to be evaluated under this model was the influence of physiological proximity in the internationalisation of a technology driven SMEs and to better understand the specific drivers of internationalisation for this sector.

The knowledge intensive Spanish SMEs seem to be motivated in their international expansion by the need to exploit their knowhow in foreign markets and they seek to internationalise in a short period of time especially in those markets with less psychic distance.

\section{References}

Acs, Z. J., \& Preston, L. (1997). Small and medium-sized enterprises, technology, and globalization: Introduction to a special issue on small and medium-sized enterprises in the global economy. Small Business Economics, 9(1), 1-6. https://doi.org/10.1023/A:1007945327618

Brynjolfsson, E., \& McAfee, A. (2014). The second machine age: work, progress, and prosperity in a time of brilliant technologies (1st ed.). New York: W. W. Norton \& Company.

Bueno, C. E., Morcillo, O. P., \& Salmador, S. M. P. (2005). Dirección estratégica, nuevas perspectivas teóricas $\left(1^{\mathrm{a}}\right)$. Madrid: Pirámide.

Chandra, Y., Styles, C., \& Wilkinson, I. (2009). The recognition of first time international entrepreneurial opportunities: Evidence from firms in knowledge-based industries. International Marketing Review, 26(1), 30-61. https://doi.org/10.1108/02651330910933195

Cohen, W. M., \& Levinthal, D. A. (1990). Absorptive Capacity: A New Perspective on Learning and Innovation. Administrative Science Quarterly, 35(1), 128-152. https://doi.org/10.2307/2393553

Corbetta, P. (2003). Social research: Theory, methods and techniques. Sage. https://doi.org/10.4135/9781849209922

Coviello, N., \& Munro, H. (1997). Network relationships and the internationalisation process of small software firms. International business review, 6(4), 361-386. https://doi.org/10.1016/S0969-5931(97)00010-3

Dunning, J. H. (2000). The eclectic paradigm as an envelope for economic and business theories of MNE activity. International Business Review, 9(2), 163-190. https://doi.org/10.1016/S0969-5931(99)00035-9

Escolano, U. S., \& Escalona, O. A. I. (2017). Especialización, concentración y aglomeración espacial de los servicios intensivos en conocimiento en España. Gènere i medi ambient, 63(1), 55-80.

European Union User guide to the SME Definition. (2015). User guide to the SME Definition,. ISBN 978-92-79-45301-4.

European Union: Background Study for the European Competitiveness. (2014). Drivers of SME Internationalization: Implications for Firm Growth and Competitiveness: Background Study for the European Competitiveness Report. Ref. Ares (2015) 901433 - 02/03/2015.

Eurostat (s/f-b). (2012). Statistic Explained. Glossary: Knowledge-intensive services (KIS). Luxembourg: Publications Office of the European Union.

FECYT; INE. (2016). Panel de Innovación Tecnológica. Obtenido de https://icono.fecyt.es/pite.

Fernández, de A. J. C., \& Arranz, P. N. (1999). La cooperación entre empresas: análisis y diseño. España. Esic Editorial.

Fernandez, O. R., \& Lombardo, G. F. (2009). Influence of the capacities of top management on the internationalization of SMEs. Entrepreneurship \& Regional Development, 21(2), 131-154. https://doi.org/10.1080/08985620802176104 
Freeman, S., Edwards, R., \& Schroder, B. (2006). How Smaller Born-Global Firms Use Networks and Alliances to Overcome Constraints to Rapid Internationalization. Journal of International Marketing, 14(3), 33-63. https://doi.org/10.1509/jimk.14.3.33

Freeman, S., Hutchings, K., Lazaris, M., \& Zyngier, S. (2010). A model of rapid knowledge development: The smaller born-global firm. International Business Review, 19(1), 70-84. https://doi.org/10.1016/j.ibusrev.2009.09.004

Gabrielsson, M., \& Kirpalani, V. H. M. (2004). Born globals: how to reach new business space rapidly. International Business Review, 13(5), 555-571. https://doi.org/10.1016/j.ibusrev.2004.03.005

Grant, R. M. (2013). Contemporary strategy analysis (8th ed.). Hoboken, NJ: Wiley.

Gupta, V., MacMillan, I. C., \& Surie, G. (2004). Entrepreneurial leadership: developing and measuring a cross-cultural construct (Vol. 19). https://doi.org/10.1016/S0883-9026(03)00040-5

Hessels, J., Gelderen, M. V., \& Thurik, R. (2008). Entrepreneurial aspirations, motivations, and their drivers. Small Business Economics, 31(3), 323-339. https://doi.org/10.1007/s11187-008-9134-X

Hsu, W. T., Chen, H. L., \& Cheng, C. Y. (2013). Internationalization and firm performance of SMEs: The moderating effects of CEO attributes. Journal of World Business, 48(1), 1-12. https://doi.org/10.1016/j.jwb.2012.06.001

Instituto Nacional de Estadística (INE). (2009). CNAE en su revisión N².

Johanson, J., \& Mattsson, L. G. (2015). Internationalisation in industrial systems a network approach (pp. 111-132). Springer.

Johanson, J., \& Vahlne, J. E. (1977). The Internationalization Process of the Firm-A Model of Knowledge Development and Increasing Foreign Market Commitments. Journal of International Business Studies, 8(1), 23-32. https://doi.org/10.1057/palgrave.jibs.8490676

Johanson, J., \& Vahlne, J. E. (2009). The Uppsala internationalization process model revisited: From liability of Foreignness to Liability of Outsidership. Journal of International Business Studies, 40(9), 1411-1431. https://doi.org/10.1057/jibs.2009.24

Jones, O., \& Crompton, H. (2009). Enterprise logic and small firms: a model of authentic entrepreneurial leadership. Journal of Strategy and Management, 2(4), 329-351. https://doi.org/10.1108/17554250911003836

Kafouros, M. I., Buckley, P. J., Sharp, J. A., \& Wang, C. (2008). The role of internationalization in explaining innovation performance. Technovation, 28(1-2), 63-74. https://doi.org/10.1016/j.technovation.2007.07.009

Kogut, B., \& Zander, U. (1992). Knowledge of the Firm, Combinative Capabilities, and the Replication of Technology. Organization Science, 3(3), 383-397. https://doi.org/10.1287/orsc.3.3.383

Madsen, T. K., \& Servais, P. (1997). The internationalization of Born Globals: An evolutionary process? International Business Review, 6(6), 561-583. https://doi.org/10.1016/S0969-5931(97)00032-2

Manyika, J., Lund, S., Bughin, J., Woetzel, J., Stamenov, K., \& Dhingra, D. (2016). Digital globalization: The new era of global flows. McKinsey Global Institute.

Morcillo, O. P. (1997). Dirección estratégica de la tecnología e innovación: un enfoque de competencias (1a ed.). Madrid: Cívitas.

Morcillo, O. P. (2007). Cultura e innovación empresarial: la conexión perfecta. International Thomson.

Muijs, D. (2010). Doing quantitative research in education with SPSS. Sage.

Muchiri, M., \& McMurray, A. (2015). Entrepreneurial orientation within small firms: a critical review of why leadership and contextual factors matter. Small Enterprise Research, 22(1), 17-31. https://doi.org/10.1080/13215906.2015.1017076

Myro, S. R., Alvarez, L. M. E., Fernández, O. C. M., Rodríguez, R. D., \& Vega, C. J. (2013). Fortalezas competitivas y sectores clave en la exportación española. Instituto de Estudios Económicos (IEE).

Narasimhan, R., Kumar, R. M. V., \& Sridhar, M. K. (2015). Internationalization of Technology-based SMEs in India: Critical Factors of Transformation. South Asian Journal of Management, 22(2), 144-166.

OECD. (2009). Top Barriers and Drivers to SME Internationalisation. Report by the OECD Working Party on SMEs and Entrepreneurship. Paris.

Olejnik, E., \& Swoboda, B. (2012). SMEs' internationalisation patterns: descriptives, dynamics and determinants. International Marketing Review, 29(5), 466-495. https://doi.org/10.1108/02651331211260340

Patton, M. Q. (1990). Qualitative evaluation and research methods. SAGE Publications, Inc. 
Saarenketo, S., Puumalainen, K., Kuivalainen, O., \& Kyläheiko, K. (2004). Dynamic knowledge-related learning processes in internationalizing high-tech SMEs. International Journal of Production Economics, 89(3), 363-378. https://doi.org///dx.doi.org/10.1016/S0925-5273(03)00185-3

Schricke, E., Zenker, A., \& Stahlecker, T. (2012). Knowledge-intensive (business) services in Europe. Brussels: European Commission.

Schumpeter J. (1966). Capitalism, Socialism and Democracy (pp. 82). London: Unwin University Books.

Schumpeter, J. (1934). The Theory of Economic Development. Harvard University Press, Cambridge, Massachusetts.

Tania, C., Stefano, C., Chiara, F. M., Francesca, R., Giuseppe, S., Michele, S., \& Irina, Z. (2014). Internet Technologies to Support SMEs' Growth in New Markets (pp. 375-398). Springer. https://doi.org/10.1007/978-3-642-38244-4_19

Tidd, J., \& Bessant, J. R. (2009). Managing innovation: Integrating technological, market and organizational change (4th ed.). Hoboken, NJ [etc.]: John Wiley \& sons.

Todd, P. R., \& Javalgi, R. (Raj) G. (2007). Internationalization of SMEs in India. International Journal of Emerging Markets, 2(2), 166-180. https://doi.org/10.1108/17468800710739234

Trochim, W. M., \& Donnelly, J. (2005). Research methods: The concise knowledge base. Atomic Dog Publishing Cincinnati, $\mathrm{OH}$.

van Zyl, H. J. C., \& Mathur, H. B. (2007). Exploring a conceptual model, based on the combined effects of entrepreneurial leadership, market orientation and relationship marketing orientation on South Africa's small tourism business performance. South African journal of business management, 38(2), 24.

Wolff, J. A., \& Pett, T. L. (2000). Internationalization of small firms: An examination of export competitive patterns, firm size, and export performance. Journal of Small Business Management, 38(2), 34-47.

Zaridis, A. D., \& Mousiolis, D. T. (2014). Entrepreneurship and SME's organizational structure. Elements of a successful business. Procedia-Social and Behavioral Sciences, 148, 463-467. https://doi.org/10.1016/j.sbspro.2014.07.066

Zeng, S. X., Xie, X. M., \& Tam, C. M. (2010). Relationship between cooperation networks and innovation performance of SMEs. Technovation, 30(3), 181-194. https://doi.org/10.1016/j.technovation.2009.08.003

\section{Appendix}

Appendix 1. Segmentation of e knowledge intensive services CNAE-2009

\begin{tabular}{ll}
\hline Group & Field of Activity 2 Digits (CNAE-2009). \\
\hline Services with intensive & 59: Cinematographic activities, video and TV programs; \\
use of knowledge and & 60: Activities of programming and broadcasting on radio and television; \\
advanced technology & 61: Telecommunications; \\
(KIS IT) & 62: Informatics programming, consulting and other informatics-related \\
& activities; \\
& 63: Information service; \\
& 72: Research and development. \\
\hline
\end{tabular}

Source: Escolano-Utrilla \& Escalona-Orcao (2017, p. 62).

Appendix 2. Endorsement of activities of CNAE-2009 to ACTIN Code

\begin{tabular}{lll}
\hline ACTIN Code & Branch of Activity & CNAE-2009 \\
\hline $\mathbf{0 0 3 2}$ & Telecommunications & 61 \\
$\mathbf{0 0 3 3}$ & Programming, Consultancy and other informatics activities & 62 \\
$\mathbf{0 0 3 4}$ & Other Information and Communication Services & $58,59,60,63$ \\
$\mathbf{0 0 3 7}$ & Other R\&D Services & 72 \\
\hline
\end{tabular}

Source: Technology Innovation Panel, PITEC (2013). 
Appendix 3. Definitions

\begin{tabular}{l}
\hline Variables \\
\hline TURNOVER \\
WORK_PRODU \\
CTIVITY \\
EXPORT_INTE \\
NSITY \\
\\
LN(EXPORTTU \\
RNOVER_TOTA \\
L+1) \\
EXPORTTURNO \\
VER_TOTAL
\end{tabular}

Descriptor and definition of Variables

Earnings from use of the business of firm X0 during 2013.

The TURNOVER of business in 2013 for firm X0 divided by SIZE of firm X0, measured on basis of number of employees.

The total exported (EXPORTTURNOVER_TOTAL) as a percentage of the total turnover of the firm. The total turnover exported is divided by the TURNOVER for 2013 for a firm X0. The result represents export intensity which then the nearer it is to 1 or $100 \%$, the higher are the exports of firm X0.

The variable corresponds to the figure for total exports EXPORTTURNOVER_TOTAL) after adding the value 1 and applying the niperian logarithm for the effect of normalizing the distribution of the variable in the linear regression model.

EXPORTTURNO The variable is constructed on the volume of exports corresponding to intra/extra community deliveries for a firm X0 during 2013. It considers both the \% EXPORTN (Export volume, not including intracommunity deliveries in 2013) and the \% INTRACOM (sales to EU countries, AELC or candidate countries for EEC entry in 2013) and is multiplied by the TURNOVER.

SIZE The number of people employed by firm X0 in 2013

EXPORT Firm X0 has exported products and services (1) or has not done so (0). The result would be positive (1) if firm X0 sends exports to MDOE (market corresponding to other European countries) and/or in ANOTHERCOUNTRY (market corresponding to countries outside the EU).

INNPROD $\quad$ Firm X0 has made product innovations (1) in $2011(\mathrm{t}-2)$ or not $(0)$

INNPROC $\quad$ Firm X0 has made process innovations (1) in $2011(\mathrm{t}-2)$ or not (0).

R\&D $\quad$ FirmX0 has made investments in R\&D in 2013 (1) or has not done so (0). The result is 1 positive when the firm X0 incurs internal expenditure on R\&D (IDIN) or when it has incurred expenditure in R\&D (IDEX).

TRAINING $\quad$ Firm 0 has spent money on training in 2013 (1) or has not (0)

GTINN The continuous variable indicates the total expenditure incurred in innovations in the firm X0 in 2013.

COOPERATES The binary variable indicates whether firm X0 has cooperated with other firms (1) in $2011(\mathrm{t}-2)$ or has not

INDUSTRIAL_ INTELLECTUA L PROTECTION Firm X0 has performed activities geared to protection of industrial and intellectual property (1) during 2011 (t-2) or did not do so (0). The condition is valid if one of the variables is positive: PAT (Request for patents), or USEMODEL (Protection use, register of useful models) or USENAME (Protection use factory names) or USEAUTHOR (Use protection: author's rights)

ACTIN Type of activity of the firm X0 according to CNAE2009

SEGMENT Firms X0 according to Activity code CNAE 2009

Other Industrial Sectors None-services (0))

Firms with technology base and knowledge-intensive (1)

Non-technological service base (2)

INORGN In $2001(\mathrm{t}-2)$ firm X0 has carried out organisational innovations (1) or has not (0). INORGN is a variable which considers both organisational innovations in new or improved management systems (INORGN1) as important organisational changes in the organisation of the firm's work (INORGN2). The positive value in some of these constructs indicates that the firm has carried out organisational innovations.

INCOMN In $2011(\mathrm{t}-2)$ firm X0 has carried out commercial innovations (1) or has not done so (0). Commercial innovations cover the following areas;

a. Significant modifications in product design or packaging of goods or services (INCCOMNI)

b. New techniques or channels for product promotion (INCOMN 2)

c. New methods for positioning the product in the market or sales outlets (INCOMN 3);

d. New methods of establishing prices of goods or services (INCOMN 4)

The positive result of some of these indicate that firm X0 has carried out commercial innovations.

WHEN Length of service X0 is constructed on the arithmetical difference between the year of FOUNDED the study (2013) and the year of creation of the company CREATIONYEAR

Source: Own adaptation on Panel of Technological Innovation (PITEC), 2013.

\section{Copyrights}

Copyright for this article is retained by the author(s), with first publication rights granted to the journal.

This is an open-access article distributed under the terms and conditions of the Creative Commons Attribution license which permits unrestricted use, distribution, and reproduction in any medium, provided the original work is properly cited. 